\title{
The prognostic role of tissue TLR2 and TLR4 in colorectal cancer
}

\author{
Ines Beilmann-Lehtonen ${ }^{1}$ (i) $\cdot$ Camilla Böckelman $^{1,2} \cdot$ Harri Mustonen $^{1} \cdot$ Selja Koskensalo ${ }^{1} \cdot$ Jaana Hagström ${ }^{3}$. \\ Caj Haglund ${ }^{1,2,3}$
}

Received: 2 October 2019 / Revised: 17 April 2020 / Accepted: 28 April 2020 / Published online: 19 May 2020

(C) The Author(s) 2020

\begin{abstract}
Colorectal cancer (CRC), the second most common cancer globally, resulted in 881,000 deaths in 2018. Toll-like receptors (TLRs) are crucial to detecting pathogen invasion and inducing the host's immune response. This study aimed to explore the prognostic value of TLR2 and TLR4 tumor expressions in colorectal cancer patients. We studied the immunohistochemical expressions of TLR2 and TLR4 using tissue microarray specimens from 825 patients undergoing surgery in the Department of Surgery, Helsinki University Hospital, between 1982 and 2002. We assessed the relationships between TLR2 and TLR4 expressions and clinicopathological variables and patient survival. We generated survival curves using the Kaplan-Meier method, determining significance with the log-rank test. Among patients with lymph node-positive disease and no distant metastases (Dukes C), a strong TLR2 immunoactivity associated with a better prognosis $(p<0.001)$. Among patients with local Dukes B disease, a strong TLR4 immunoactivity associated with a worse disease-specific survival (DSS; $p=0.017$ ). In the multivariate survival analysis, moderate TLR4 immunoactivity compared with strong TLR4 immunoactivity (hazard ratio (HR) $0.66,95 \%$ confidence interval (CI) $0.49-0.89, p=0.007)$ served as an independent prognostic factor. In the multivariate analysis for the Dukes subgroups, moderate TLR2 immunoactivity (HR 2.63, 95\% CI 1.56-4.44, $p<0.001$ ) compared with strong TLR2 immunoactivity served as an independent negative prognostic factor in the Dukes C subgroup. TLR2 and TLR4 might be new prognostic factors to indicate which CRC patients require adjuvant therapy and which could spare from an unnecessary followup, but further investigations are needed.
\end{abstract}

Keywords Toll-like receptor $2 \cdot$ Toll-like receptor $4 \cdot$ Colorectal cancer $\cdot$ Colon cancer $\cdot$ Immunohistochemistry

$\begin{array}{ll}\text { Abbreviations } \\ \text { TLR } & \text { Toll-like receptor } \\ \text { TLR2 } & \text { Toll-like receptor 2 } \\ \text { TLR4 } & \text { Toll-like receptor } 4 \\ \text { CRC } & \text { Colorectal cancer }\end{array}$

Electronic supplementary material The online version of this article (https://doi.org/10.1007/s00428-020-02833-5) contains supplementary material, which is available to authorized users.

Ines Beilmann-Lehtonen ines.beilmann-lehtonen@hus.fi
CI Confidence interval

HR Hazard ratio

IQR Interquartile range

TMA Tissue microarray

CRP C-reactive protein

TME Tumor microenvironment

SIR Systemic inflammatory response

DSS Disease-specific survival

DC Dendritic cell

MyD88 Myeloid differentiation primary response gene 88

IBD Inflammatory bowel disease

NF- B Nuclear factor B

\section{Introduction}

Colorectal cancer (CRC) represents a major burden for public healthcare systems as the third most common malignancy globally and the second leading cause of cancer deaths. In 2018, more than 1.8 million new cases were diagnosed and 
881,000 CRC deaths occurred [1]. A wide geographical difference in CRC burden exists, with a threefold higher incidence and about $55 \%$ of all deaths occurring in transitioning countries [1-3]. The CRC burden is expected to increase given the aging and growth of populations and the adoption of a so-called Western lifestyle [3].

CRC survival in developed countries has increased given improved screening and treatment, although $17 \%$ of stage II and $36 \%$ of stage III tumors still recur within 5 years. Identifying patients that need thorough follow-up and adjuvant therapy remains important, whereas other patients could be spared unnecessary treatment and possibly follow-up [4].

Chronic inflammation serves as an important risk factor for cancer. Both the local tumor microenvironment (TME) and the systemic host response play crucial roles in the development and progression of cancer [5, 6]. Reports have indicated that the host's systemic inflammatory response (SIR), evidenced by an elevated preoperative C-reactive protein (CRP) value, predicts a shorter survival period among patients undergoing primary tumor resection $[7,8]$. Yet, local inflammation found specifically in the invasive area of the tumor predicts better survival [9].

Toll-like receptors (TLR) represent a large family of pattern recognition receptors expressed on immune cells and epithelial cells and play a crucial role in the innate immune response since they detect pathogens and induce pro-inflammatory immune responses [5, 10-12]. Yet, TLR expression patterns vary across different immune cells. In endothelial cells, for example, TLR2 and TLR4 express intracellularly, whereas, in leukocytes such as monocytes, macrophages, neutrophils, dendritic cells (DCs), and natural killer (NK) cells, TLR2 and TLR4 expressed on the cell membranes [13].

TLRs work through the myeloid differentiation primary response gene 88 (myD88) pathway common to all TLRs. Furthermore, TLR3 and TLR4 work through the myD88independent pathways [5, 10-12]. Additionally, TLRs induce the maturation of DCs leading to T cell activation and differentiation into effector cells, necessary for initiating an adaptive immune response. Thus, TLR signaling represents an important link between the host's innate and adaptive immune responses $[10,14,15]$.

Alongside exogenous microbial ligands, TLRs also recognize several endogenous host-derived ligands released during tissue damage and tumor progression [5, 10-13]. TLRs are also known to take part in the pathogenesis of several autoimmune, chronic inflammatory, and infectious diseases including rheumatoid arthritis [16], type 1 and 2 diabetes [17, 18], psoriasis [10], Crohn's disease [19], and ulcerous colitis [20].

Several studies showed that TLRs play a role in cancer pathogenesis. TLRs express on tumor cells, while dying tumor cells release endogenous TLR ligands, thus activating TLR signaling and promoting tumorigenesis [21-23]. It is thought that different TLRs carry specific and different protumoral and/or antitumoral roles in different tumors [12]. In relation to CRC, no prognostic value has been found for TLR2, while contradictory results have emerged for TLR4 [24-27]. Therefore, this study aimed to clarify the prognostic roles of TLR2 and TLR4 in colorectal cancer.

\section{Materials and methods}

\section{Patients}

Our cohort consisted of 825 patients undergoing a primary operation for CRC at the Department of Surgery, Helsinki University Hospital, between 1982 and 2002. Among these patients, 457 (55.4\%) were male. The median age was 67.5 years (interquartile range (IQR) 57.6-75.3 years). The tumor was located in the rectum in $401(48.6 \%)$ patients and in the colon in 424 (51.4\%) patients.

The median follow-up time was 5.1 years (IQR 1.2-17.2) and $641(77.7 \%)$ patients died by the end of the follow-up period. The 5-year disease-specific survival (DSS) was $58.9 \%$ (95\% confidence interval (CI) 55.4-62.4). Among right-sided cancer patients, 5 -year DSS rates were $58.1 \%$ (95\% CI 51.4-64.8) and 59.2\% (95\% CI 55.1-63.3) among left-sided cancer patients. Among 292 stage 2 patients, 25 $(8.6 \%)$ received adjuvant therapy, while $53(23.6 \%)$ of 225 stage 3 patients received adjuvant therapy, and 62 of 186 $(33.3 \%)$ stage 4 patients received adjuvant therapy.

At the time of patient recruitment, we used the modified Dukes staging for CRC in our clinic. As such, 122 cases tumor were classified as Dukes stage A (14.8\%), 292 cases as Dukes B (35.4\%), 225 as Dukes C (27.3\%), and 186 as Dukes D (22.5\%). Table 1 summarizes the patients' clinicopathological characteristics.

We received the clinical data from patients' medical records and the survival data and causes of death from the Population Register Center of Finland and Statistics Finland. The Surgical Ethics Committee of Helsinki University Hospital (Dnro HUS 226/E6/06, extension TMK02 §66 17.4.2013) approved the study protocol. The National Supervisory Authority of Health and Welfare granted permission to use tissue archive samples retrospectively without requiring individual consent (Valvira Dnro 10041/06.01.03.01/ 2012).

\section{Tissue samples}

Surgical tumor samples fixed in formalin and embedded in paraffin were stored in the archives of the Department of Pathology at the University of Helsinki. Histopathologically representative areas of the tumor samples were marked on hematoxylin- and eosin-stained slides by an experienced pathologist (JH). From the annotated areas, three $1.0-\mathrm{mm}$ cores 
Table 1 Characteristics of colorectal cancer patients

\begin{tabular}{ll}
\hline Patient characteristics & $n(\%)$ \\
\hline Age & \\
Median (IQR), years & $67.5(57.6-75.3)$ \\
Gender & \\
Male & $457(55.4)$ \\
Female & $368(44.6)$ \\
Dukes stage & \\
A & $122(14.8)$ \\
B & $292(35.4)$ \\
C & $225(27.3)$ \\
D & $186(22.5)$ \\
Tumor grade (WHO) & \\
1 & $26(3.2)$ \\
2 & $563(68.4)$ \\
3 & $201(24.4)$ \\
4 & $33(4.0)$ \\
Location & \\
Colon & $424(51.4)$ \\
Rectum & $401(48.6)$ \\
Side & $225(27.3)$ \\
Light & $600(72.7)$ \\
Histological type & \\
Adeno & \\
\hline & \\
Mucinous & \\
\hline
\end{tabular}

$I Q R$, interquartile range

were punched from each tumor and embedded in a recipient paraffin block with a semiautomatic tissue arrayer (Beecher Instruments Inc., Silver Spring, MD, USA). Sections of $4 \mu \mathrm{m}$ were cut from the tissue microarray (TMA) blocks for immunohistochemistry.

\section{Immunohistochemistry}

Slides with TMA block sections were deparaffinized in xylene and then rehydrated in solutions containing a decreasing concentration of ethanol, beginning with pure alcohol and ending with distilled water. The antigen retrieval was accomplished by treating the slides in a PreTreatment module (Lab Vision UK Ltd., UK) in a Tris-HCl buffer ( $\mathrm{pH} \mathrm{8.5)} \mathrm{for} 20 \mathrm{~min}$ at $98^{\circ} \mathrm{C}$.

Staining of the slides was carried out in an Autostainer 480 (Lab Vision, Fremont, CA, USA) using the REAL EnVision Detection System (peroxidase/DAB+, rabbit/mouse; Dako, Glostrup, Denmark). The inactivation of endogenous peroxidases was completed by incubating the slides in $0.3 \%$ hydrogen peroxide for $5 \mathrm{~min}$. Subsequently, the primary incubation with rabbit polyclonal antibodies against TLR4 (H-80; Santa
Cruz Biotechnology, Santa Cruz, CA, USA; diluted to 1:50) or TLR2 (H-175; Santa Cruz Biotechnology, Santa Cruz, CA, USA; diluted to 1:50) was carried out for $1 \mathrm{~h}$, followed by incubation with the Dako REAL EnVision/HRP detection system using the Rabbit (ENV) reagent for $30 \mathrm{~min}$. Finally, stainings were visualized using the Dako REAL DAB+ Chromogen for $10 \mathrm{~min}$. Between each step, the slides were washed in PBS $0.04 \%$ Tween20. Slides were counterstained with Meyer's hematoxylin and finally mounted in Pertex Mounting (Histolab Products AB, Sweden). Tissues showing a high immunoreactivity for these antigens were used as the positive controls (tonsillar and gums). Specimens processed without any primary antibody were used as the negative controls. We have compared the results of TLR4 stainings of a small cohort with the new TLR4 mouse monoclonal antibody (sc-293072, Santa Cruz Biotechnology, Santa Cruz, CA, USA), the immunoexpression of TLR4 by the two different antibodies correlated $\left(r_{\mathrm{s}}=0.721, p<0.001\right.$, Spearman's rank correlation test).

\section{Scoring}

Two researchers (IB-L and JH) independently scored the TLR2 and TLR4 immunostainings. TLR2 and TLR4 immunopositivity was defined as a brown cytoplasmic color in the tumor cells scored from 0 to 3 reflecting the staining intensity. Here, 0 represented negative staining and no immunoactivity, 1 represented a weak positive immunoactivity, 2 represented a moderate intensity of staining, and 3 represented a strong intensity of staining (Fig. 1). If three scores of the same patient were different, the highest score was used. The scores of both researchers were compared, and cases with any variance were assigned a final score reached through consensus.

\section{Statistical analysis}

For the statistical analysis, we grouped TLR2 and TLR4 immunoexpressions into low (0), moderate (1-2), and high (3) expression levels. The associations between the TLR2 and TLR4 scoring and clinicopathological variables were analyzed used the chi-square test. DSS was calculated from the day of surgery to death from CRC. Survival curves were calculated using the Kaplan-Meyer method and the $p$ values were calculated using the log-rank test.

For the univariate and multivariate survival analyses, we used the Cox proportional hazards model, adjusting the multivariate analysis for the tumor stage, differentiation, and location. The Cox model assumption of constant hazard ratios over time was tested through the inclusion of a timedependent covariate separately for each variable tested.

A time-dependent variable was included for stage D, location, and differentiation to fulfill the Cox assumption. We also 


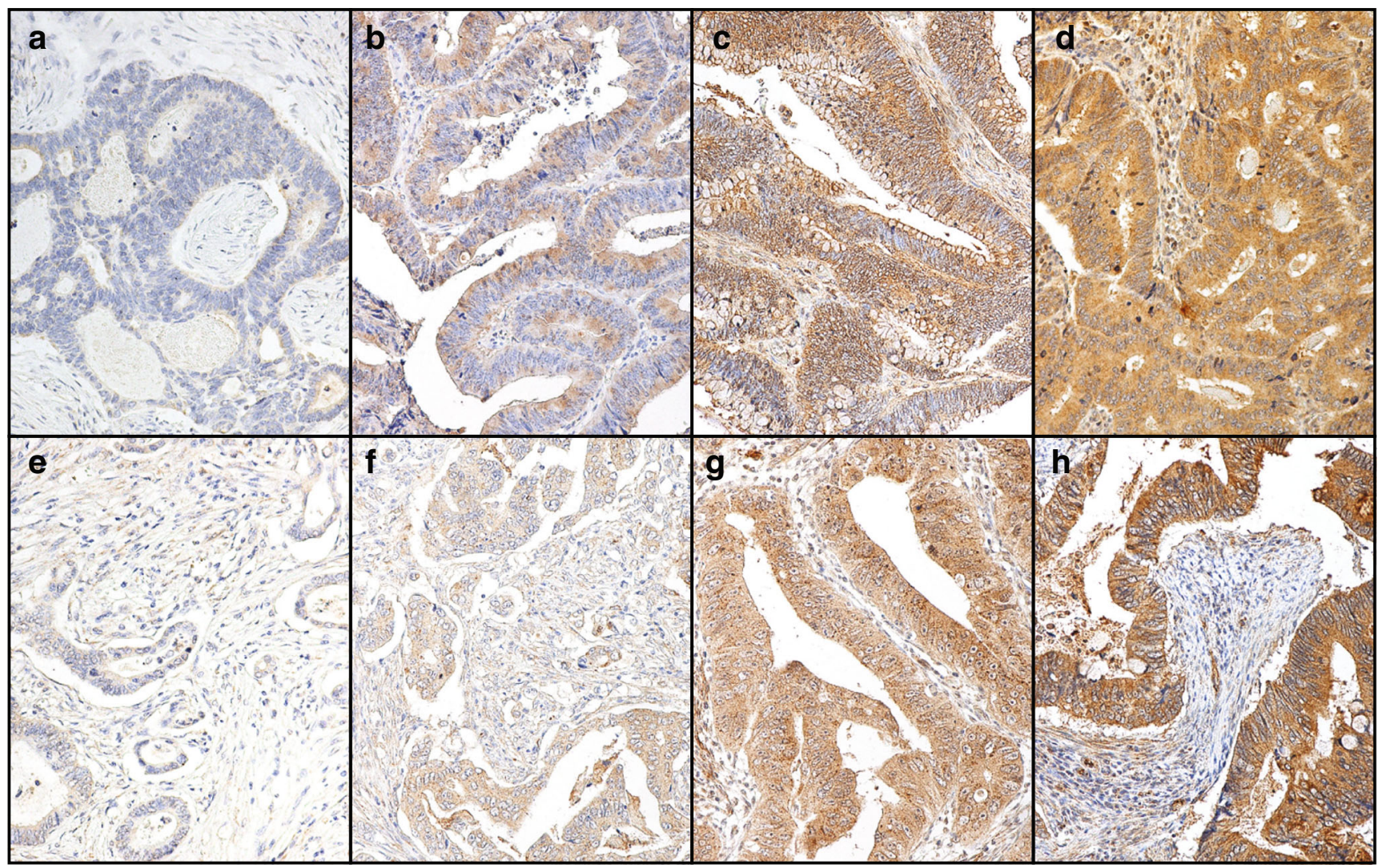

Fig. 1 Images of TLR2 and TLR4 immunohistochemistry stainings representing colorectal cancer tumors with negative $(\mathbf{a}, \mathbf{e})$, weak $(\mathbf{b}, \mathbf{f})$, moderate $(\mathbf{c}, \mathbf{g})$, and strong $(\mathbf{d}, \mathbf{h})$ staining. Images $\mathbf{a}-\mathbf{d}$ are stained with a
TLR2 polyclonal antibody and images $\mathbf{e}-\mathbf{h}$ are stained with a TLR4 polyclonal antibody. Original magnification $\times 20$

the statistical analysis, patients fell into three groups, scored as 0 (negative), 1-2 (mild and moderate), and 3 (high; Fig. 1a-d).

\section{Immunostaining for TLR4}

TLR4 stained evenly in the cytoplasm of 769 (93.2\%) samples. The immunostaining of TLR4 was not possible to interpret in $6.8 \%$ of patients for reasons mentioned above for TLR2. The immunopositivity was scored as strong in 101 (13.1\%) samples, moderate in 358 (46.6\%), weak in 273 (35.5\%), and no immunopositivity was identified in 37 (4.8\%) samples. Here, patients fell into three groups, scored as 0 (negative), 1-2 (mild and moderate), and 3 (high; Fig. 1e-h).

\section{Association with clinicopathological parameters}

munostaining proved successful in $775(93.9 \%)$ samples. The immunostaining of TLR2 was not possible to interpret appropriately in $6.1 \%$ of patients due to technical staining problems or due to missing cancer tissue.

TLR2 stained evenly in the cytoplasm. The immunopositivity was scored as strong in 200 (25.8\%) samples, moderate in 313 (40.4\%), and weak in 209 (27.0\%), and no immunopositivity was identified in $53(6.8 \%)$ samples. In
Table 2 summarizes the relationships between the clinicopathological variables and TLR2 immunointensity, while Table 3 provides the relationships with the TLR4 immunointensity. TLR2 associated with the tumor location $(p=0.042)$ and the tumor grade ( $p=0.004$, chi-square test, Table 2$)$. TLR4 associated with gender $(p=0.006)$ and the tumor grade $(p<0.001$, chi-square test, Table 3). Neither TLR2 nor TLR4 

TLR2 immunointensity and clinicopathological parameters among colorectal cancer patients
Table 2 Association between

\begin{tabular}{|c|c|c|c|c|c|}
\hline \multirow[t]{2}{*}{ Clinicopathological variable } & \multirow[t]{2}{*}{$n$} & \multicolumn{3}{|l|}{ TLR } & \multirow[t]{2}{*}{$p$ value $^{1}$} \\
\hline & & $\begin{array}{l}0 \\
n(\%)\end{array}$ & $\begin{array}{l}1 \text { and } 2 \\
n(\%)\end{array}$ & $\begin{array}{l}3 \\
n(\%)\end{array}$ & \\
\hline \multicolumn{6}{|l|}{ Age } \\
\hline $\begin{array}{l}<65 \\
\geq 65\end{array}$ & $\begin{array}{l}330 \\
445\end{array}$ & $\begin{array}{l}23(7.0) \\
30(6.7)\end{array}$ & $\begin{array}{l}217(65.8) \\
305(68.5)\end{array}$ & $\begin{array}{l}90(27.3) \\
110(24.7)\end{array}$ & 0.701 \\
\hline \multicolumn{6}{|l|}{ Gender } \\
\hline $\begin{array}{l}\text { Male } \\
\text { Female }\end{array}$ & $\begin{array}{l}428 \\
347\end{array}$ & $\begin{array}{l}29(6.8) \\
24(6.9)\end{array}$ & $\begin{array}{l}296(69.2) \\
226(65.1)\end{array}$ & $\begin{array}{l}103(24.1) \\
97(28.0)\end{array}$ & 0.452 \\
\hline \multicolumn{6}{|l|}{ Side } \\
\hline $\begin{array}{l}\text { Right } \\
\text { Left }\end{array}$ & $\begin{array}{l}217 \\
558\end{array}$ & $\begin{array}{l}19(8.8) \\
34(6.1)\end{array}$ & $\begin{array}{l}138(63.6) \\
384(68.8)\end{array}$ & $\begin{array}{l}60(27.6) \\
140(25.1)\end{array}$ & 0.266 \\
\hline \multicolumn{6}{|l|}{ Location } \\
\hline $\begin{array}{l}\text { Colon } \\
\text { Rectum }\end{array}$ & $\begin{array}{l}403 \\
372\end{array}$ & $\begin{array}{l}28(6.9) \\
25(6.7)\end{array}$ & $\begin{array}{l}256(63.5) \\
266(71.5)\end{array}$ & $\begin{array}{l}119(29.5) \\
81(21.8)\end{array}$ & 0.042 \\
\hline \multicolumn{6}{|l|}{ Histological type } \\
\hline $\begin{array}{l}\text { Adeno } \\
\text { Mucinous }\end{array}$ & $\begin{array}{l}689 \\
85\end{array}$ & $\begin{array}{l}42(6.1) \\
11(12.9)\end{array}$ & $\begin{array}{l}467(67.8) \\
55(64.7)\end{array}$ & $\begin{array}{l}180(26.1) \\
19(22.4)\end{array}$ & 0.058 \\
\hline \multicolumn{6}{|l|}{ Dukes stage } \\
\hline $\begin{array}{l}\text { A } \\
\text { B } \\
\text { C } \\
\text { D }\end{array}$ & $\begin{array}{l}110 \\
279 \\
210 \\
176\end{array}$ & $\begin{array}{l}12(10.9) \\
16(5.7) \\
14(6.7) \\
11(6.3)\end{array}$ & $\begin{array}{l}76(69.1) \\
189(67.7) \\
139(66.2) \\
118(67.0)\end{array}$ & $\begin{array}{l}22(20.0) \\
74(26.5) \\
57(27.1) \\
47(26.7)\end{array}$ & 0.537 \\
\hline \multicolumn{6}{|l|}{ Tumor grade (WHO) } \\
\hline $\begin{array}{l}1 \\
2 \\
3 \\
4\end{array}$ & $\begin{array}{l}24 \\
529 \\
189 \\
31\end{array}$ & $\begin{array}{l}5(20.8) \\
33(6.2) \\
9(4.8) \\
6(19.4)\end{array}$ & $\begin{array}{l}11(45.8) \\
356(67.3) \\
135(71.4) \\
18(58.1)\end{array}$ & $\begin{array}{l}8(33.3) \\
140(26.5) \\
45(23.8) \\
7(22.6)\end{array}$ & 0.004 \\
\hline
\end{tabular}

TLR2, Toll-like receptor 2

${ }^{1}$ Chi-square test

immunoexpression associated with patient age, the histological type of tumor, or the Dukes tumor stage.

\section{Survival analysis}

In the DSS analysis, we found no difference between the different TLR2 ( $p=0.199$, log-rank test) or TLR4 expression groups ( $p=0.240$, log-rank test; data not shown).

In the subgroup analysis, TLR2 emerged as a prognostic factor among the Dukes $\mathrm{C}$ patients, that is, those with lymph node-positive but distant metastasis-free disease (Fig. 2c; $p<0.001$, log-rank test). In this subgroup, the 5-year DSS was $68.4 \%$ (95\% CI 42.7-94.1) among patients with a negative TLR2 immunostaining and 72.6\% (95\% CI 60.6-84.6) among those with a strong TLR2 immunostaining compared with 48.2\% (95\% CI 39.2-57.3) among patients with a moderate TLR2 immunostaining. Among the subgroups, Dukes A (Fig. 2a), B (Fig. 2b), and D (Fig. 2d) patients, TLR2 did not serve as a prognostic factor.

By contrast, TLR4 immunostaining served as a negative prognostic factor among Dukes B patients (Fig. 3b; $p=$
0.017, log-rank test). A 5-year DSS reached $100 \%$ among TLR4-negative patients, 80.6\% (95\% CI 75.1-86.1) among TLR4-moderate patients, and $66.1 \%$ (95\% CI 51.0-81.2) among TLR4-strong immunostaining patients. Among the Dukes A (Fig. 3a), Dukes C (Fig. 3c), and Dukes D (Fig. 3d) subgroups, TLR4 did not serve as a prognostic factor.

In the subgroup analysis among patients who did not receive adjuvant therapy, the results mirrored those among the entire cohort. Among Dukes $\mathrm{C}$ patients who did not receive adjuvant therapy, a very strong TLR2 expression predicted a better survival compared with those patients with a moderate TLR2 expression (Suppl. Fig. 2c; $p<0.001$, log-rank test). Among Dukes B patients who did not receive adjuvant therapy, a strong TLR4 immunoexpression showed a worse prognosis (Suppl. Fig. 3b; $p=0.01$, log-rank test). In the Cox univariate survival analysis, patients over 65 years of age $(p=$ $0.001)$, patients with less differentiated cancer $(p=0.001)$, and patients with higher Dukes stages $(p<0.001)$ exhibited worse prognoses. In the Cox multivariate survival analysis adjusted for age, gender, Dukes stage, the tumor grade, and tumor location, a moderate TLR4 immunoreactivity (HR 0.66, 
Table 3 Association between TLR4 immunointensity and clinicopathological parameters in colorectal cancer patient

\begin{tabular}{|c|c|c|c|c|c|}
\hline \multirow[t]{2}{*}{ Clinicopathological variable } & \multirow[t]{2}{*}{$n$} & \multicolumn{3}{|l|}{ TLR4 } & \multirow[t]{2}{*}{$p$ value $^{1}$} \\
\hline & & $\begin{array}{l}0 \\
n(\%)\end{array}$ & $\begin{array}{l}1 \text { and } 2 \\
n(\%)\end{array}$ & $\begin{array}{l}3 \\
n(\%)\end{array}$ & \\
\hline \multicolumn{6}{|l|}{ Age } \\
\hline$<65$ & 323 & $20(6.2)$ & $264(81.7)$ & $39(12.1)$ & \multirow[t]{2}{*}{0.204} \\
\hline$\geq 65$ & 443 & $16(3.6)$ & $365(82.4)$ & $62(14.0)$ & \\
\hline \multicolumn{6}{|l|}{ Gender } \\
\hline Male & 428 & $28(6.5)$ & $354(82.7)$ & $46(10.7)$ & \multirow[t]{2}{*}{0.006} \\
\hline Female & 341 & $9(2.6)$ & $277(81.2)$ & $55(16.1)$ & \\
\hline \multicolumn{6}{|l|}{ Side } \\
\hline Right & 214 & $13(6.1)$ & $177(82.7)$ & $24(11.2)$ & \multirow[t]{2}{*}{0.4} \\
\hline Left & 555 & $24(4.3)$ & $454(81.8)$ & 77 (13.9) & \\
\hline \multicolumn{6}{|l|}{ Location } \\
\hline Colon & 404 & $18(4.59)$ & $330(81.7)$ & $56(13.9)$ & \multirow[t]{2}{*}{0.748} \\
\hline Rectum & 365 & $19(5.2)$ & $301(82.5)$ & $45(12.3)$ & \\
\hline \multicolumn{6}{|l|}{ Histological type } \\
\hline Adeno & 689 & $29(4.2)$ & $570(82.7)$ & $90(13.1)$ & \multirow[t]{2}{*}{0.061} \\
\hline Mucinous & 79 & $8(10.1)$ & $60(75.9)$ & $11(13.9)$ & \\
\hline \multicolumn{6}{|l|}{ Dukes stage } \\
\hline A & 114 & $9(7.9)$ & $90(78.9)$ & $15(13.2)$ & \multirow[t]{4}{*}{0.342} \\
\hline $\mathrm{B}$ & 273 & $8(2.9)$ & $223(81.7)$ & $42(15.4)$ & \\
\hline $\mathrm{C}$ & 208 & $11(5.3)$ & $175(84.1)$ & $22(12.6)$ & \\
\hline $\mathrm{D}$ & 174 & $9(5.2)$ & $143(82.2)$ & $22(12.6)$ & \\
\hline \multicolumn{6}{|l|}{ Tumor grade (WHO) } \\
\hline 1 & 25 & $1(4.0)$ & $22(88.0)$ & $2(8.0)$ & \multirow[t]{4}{*}{$<0.001$} \\
\hline 2 & 528 & $23(4.4)$ & $431(81.6)$ & $74(14.0)$ & \\
\hline 3 & 185 & $5(2.7)$ & $158(85.9)$ & $21(11.4)$ & \\
\hline 4 & 30 & $8(26.7)$ & $19(63.3)$ & $3(10.0)$ & \\
\hline
\end{tabular}

TLR4, Toll-like receptor 4

${ }^{1}$ Chi-square test

95\% CI 0.49-0.89, $p=0.007)$ compared with a strong TLR4 tumor expression served as an independent prognostic factor (Table 4). In the Cox multivariate analysis including the same clinicopathological parameters and TLR2, the TLR2 immunoreactivity did not serve as prognostic factor (data not shown). In the Cox multivariate analysis for the Dukes C subgroup, a moderate TLR2 immunoactivity (HR 2.63, 95\% CI 1.56-4.44, $p<0.001$ ) compared with a strong TLR2 immunoreactivity served as an independent negative prognostic factor (Table 5). In the Cox multivariate analysis, adjuvant therapy did not serve as prognostic factor (Suppl. Table 1, $p=0.747)$.

\section{Discussion}

Among CRC patients with lymph node metastases but no distant metastases (Dukes C), a very strong expression of TLR2 predicted a remarkably better survival compared with those patients with a moderate expression. Among patients with a Dukes B tumor, a strong TLR4 immunoexpression indicated a worse prognosis. A survival analysis among patients who did not receive adjuvant therapy revealed similar results. A strong TLR4 expression in the tumor served as an independent prognostic factor.

CRC patients with tumors that have progressed to regional lymph nodes or metastasized to other organs are typically treated with postoperative chemotherapy. However, a portion of such patients still die from recurrent disease. Yet, some patients with lymph node-positive disease survive cancer without adjuvant treatment and some patients with seemingly local disease die from recurrent disease. Thus, discussions in the literature continue regarding which patients should receive adjuvant therapy and which may be spared therapy $[4,28]$. Here, we have identified a potential role for prognostic biomarkers such as TLRs.

A recent study investigated the roles of TLR2 and TLR4 in 118 CRC patients [24]. Among such patients, the intensity and extent of staining were studied separately in the tumor, the 

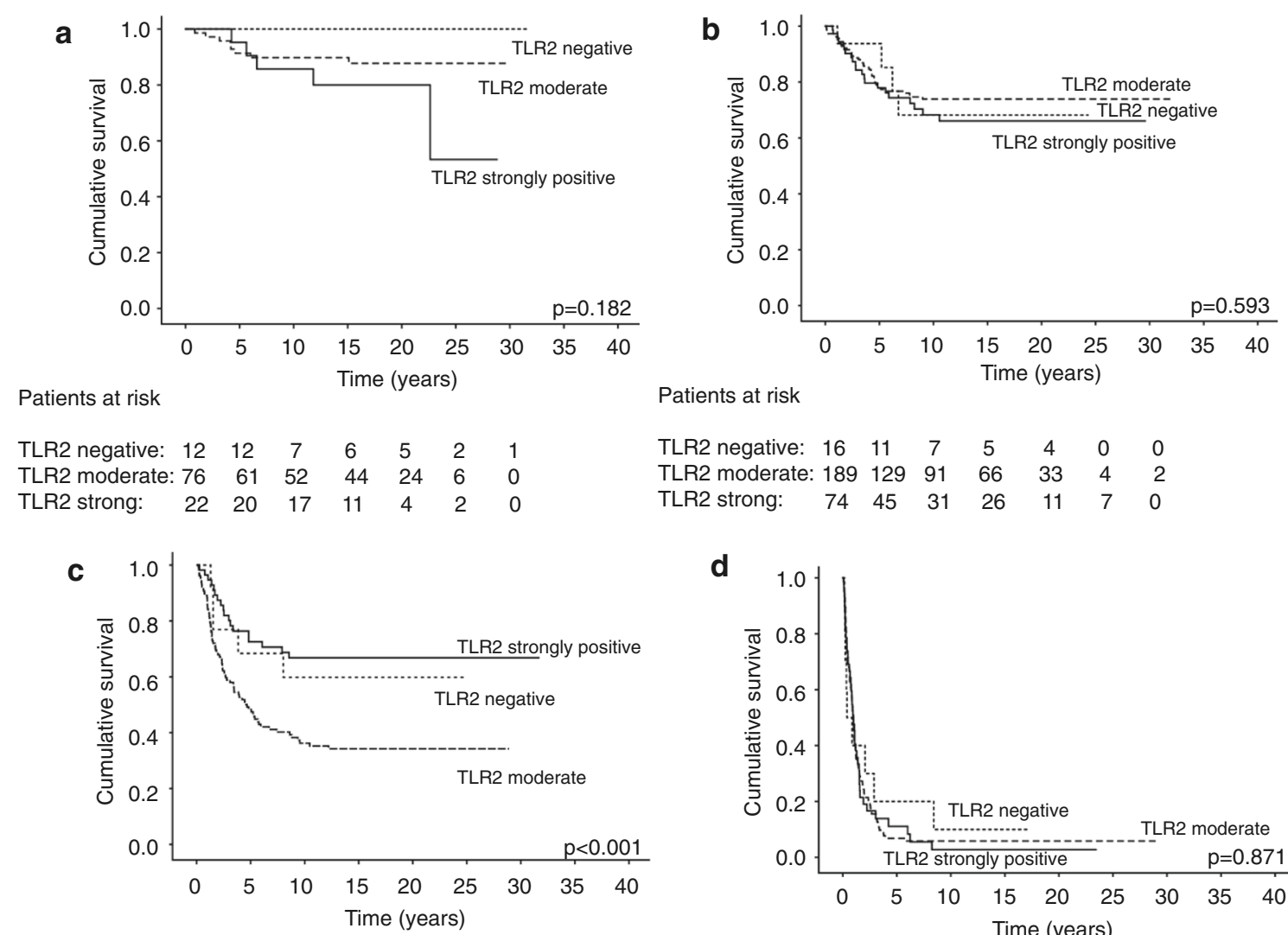

Patients at risk

$\begin{array}{llllllll}\text { TLR2 negative: } & 16 & 11 & 7 & 5 & 4 & 0 & 0 \\ \text { TLR2 moderate: } & 189 & 129 & 91 & 66 & 33 & 4 & 2 \\ \text { TLR2 strong: } & 74 & 45 & 31 & 26 & 11 & 7 & 0\end{array}$

$\begin{array}{lllllcll}\text { TLR2 negative: } & 14 & 8 & 6 & 6 & 5 & 0 & 0 \\ \text { TLR2 moderate: } & 139 & 55 & 36 & 31 & 16 & 3 & 0 \\ \text { TLR2 strong: } & 57 & 38 & 29 & 23 & 9 & 8 & 1\end{array}$

d

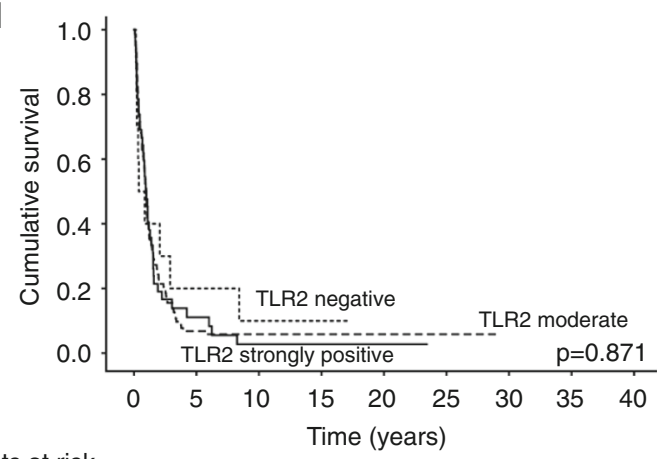

Patients at risk

$\begin{array}{llllllll}\text { TLR2 negative: } & 11 & 2 & 2 & 1 & 0 & 0 & 0 \\ \text { TLR2 moderate: } & 118 & 7 & 6 & 4 & 2 & 1 & 0 \\ \text { TLR2 strong: } & 47 & 4 & 1 & 0 & 0 & 0 & 0\end{array}$

Fig. 2 Disease-specific survival analysis of TLR2 in colorectal cancer patients using the Kaplan-Meier method. a Dukes A, b Dukes B, c Dukes C, d and Dukes D patients. The log-rank test was used

invasive border, the normal mucosa, and lymph node metastases if present. TLR4 expression was significantly stronger in the normal mucosa and in lymph node metastases compared with that in the tumor. The opposite emerged for TLR2 expression, which increased in carcinoma cells and stained at a weaker intensity in the lymph nodes than in the bulk and invasive front of the tumor. In that study in contrast to our findings here, researchers found no significant association between TLR2 and TLR4 tumor expressions and patient survival. In their study, TLR2 and TLR4 were expressed in all tumors, whereas in our series, a few tumors lacked TLR expression.

In another study, Nihon-Yanagi et al. found a higher TLR2 expression in cancer samples at each stage compared with that in the normal mucosa [26]. Furthermore, TLR2 was more intensively expressed in stage II and III tumors. In their study, TLR4 expression in carcinoma tissues mirrored that in the normal mucosa. The discrepancy between these findings and our results may be explained by their smaller patient sample size $(n=50)$, the different detection methods, and the different antibodies used. For instance, Nihon-Yanagi et al. studied the TLR4 and TLR2 expressions using real-time PCR and TLR immunoexpression from whole sections, whereas we used TMA slides and immunohistochemistry alone.

Additionally, Eiró et al. found that a high TLR4 expression in CRC tumor cells relates to a lower recurrence rate [29]. Our findings did not agree with this result. While we used the same antibody, we found that a strong TLR4 expression predicted a worse prognosis in lymph node-negative disease. Eiró et al. reported 63 Dukes B diseased patients from a patient cohort of 104. Additionally, they report of 70 lymph node-positive patients from the same cohort of 104, a figure which appears somewhat problematic. In their study, TLR4 positivity was located on the cell membranes, whereas we found cytoplasmic expression.

In another study, Siminatonaki et al. using Western blot and immunohistochemistry found a positive correlation between TLR4 downregulation and the occurrence of lymphogenous and hematogenous metastases in 115 CRC patients [27]. In our study, however, among Dukes B patients, TLR4 overexpression indicated a worse prognosis, although among Dukes $\mathrm{C}$ and D tumors, we found no significant relationship. Siminatonaki et al. additionally reported a TLR4 positivity in both the cytoplasm and cell membranes, whereas we 
a

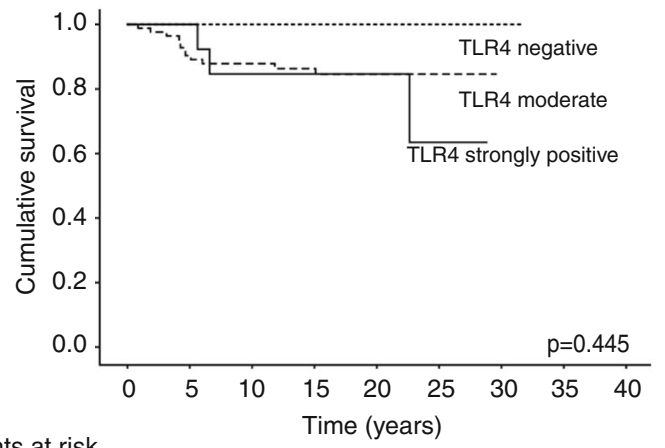

Patients at risk

$\begin{array}{lccccccc}\text { TLR4 negative: } & 9 & 9 & 7 & 7 & 2 & 1 & 0 \\ \text { TLR4 moderate: } & 90 & 74 & 61 & 50 & 28 & 9 & 0 \\ \text { TLR4 strong: } & 15 & 13 & 11 & 7 & 4 & 1 & 0\end{array}$

C

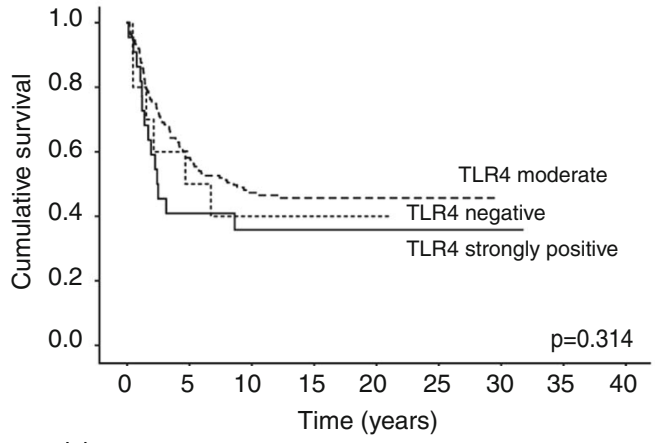

Patients at risk

TLR4 negative: $\begin{array}{llllllll}11 & 5 & 4 & 3 & 1 & 0 & 0\end{array}$

TLR4 moderate: $\begin{array}{lllllll}175 & 85 & 59 & 49 & 25 & 10 & 0\end{array}$

$\begin{array}{llllllll}\text { TLR4 strong: } \quad 22 & 8 & 7 & 6 & 3 & 2 & 1\end{array}$ b

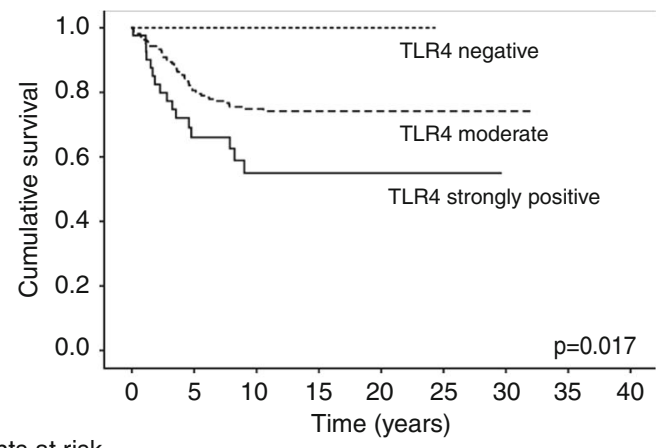

Patients at risk

$\begin{array}{llllllll}\text { TLR4 negative: } & 8 & 8 & 5 & 3 & 2 & 1 & 1 \\ \text { TLR4 moderate: } & 223 & 153 & 108 & 82 & 40 & 9 & 2\end{array}$

TLR4 strong: $\begin{array}{lllllll}42 & 21 & 13 & 10 & 4 & 1 & 0\end{array}$

d

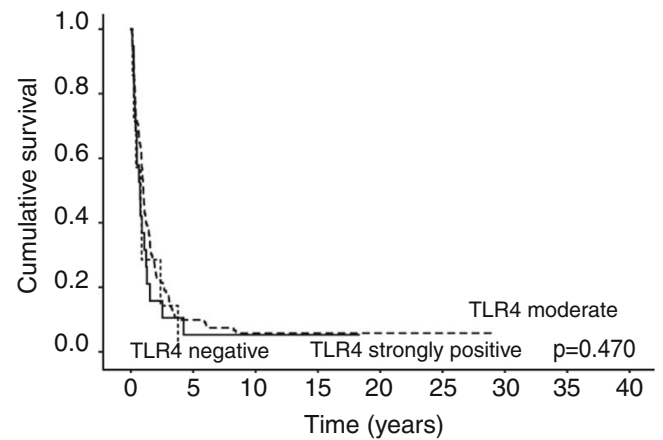

Patients at risk

$\begin{array}{llllllll}\text { TLR4 negative: } & 9 & 0 & 0 & 0 & 0 & 0 & 0\end{array}$

TLR4 moderate: $\begin{array}{llllllll}143 & 12 & 7 & 5 & 3 & 1 & 0\end{array}$

TLR4 strong: $\begin{array}{llllllll}22 & 1 & 1 & 1 & 0 & 0 & 0\end{array}$

Fig. 3 Disease-specific survival analysis of TLR4 in colorectal cancer patients using the Kaplan-Meier method. a Dukes A, b Dukes B, c Dukes C, d and Dukes D patients. The log-rank test was used

observed immunopositivity primarily in the cytoplasm, despite using the same antibody.

TLR signaling plays an important role in different cancers and the role of TLR expression can apparently vary between different cancers [12]. In Barrett's metaplasia, the TLR4 protein expression appears upregulated, with the expression intensity correlating with a poor prognosis and with the degree of dysplasia in esophageal squamous cell carcinoma development [30]. During the early stage of oral tongue squamous cell carcinoma, TLR2 and TLR4 expressions serve as predictive markers of invasive tumor growth and a higher tumor grade [31]. The nuclear TLR2 expression level can predict tumor recurrence and neck metastases of tongue cancer [32]. Previous studies demonstrated that, in pancreatic ductal adenocarcinoma, TLR2 and TLR4 serve as positive predictors of prognosis in stage I and II disease and in patients with smallsize tumors [33]. In murine and human gastric tumors, TLR2 appears upregulated and associates with a poorer overall survival in humans [34].

An increased TLR4 expression has been associated with tumor size and distant metastases in breast cancer [35], a higher recurrence rate in prostate cancer [36], and a poorer overall survival rate in ovarian cancer [37]. Additionally, an increased TLR4 expression associated with a shorter relapse-free survival time in cutaneous malignant melanomas [25], a poorer differentiation state in lung cancer [38], and a larger tumor size in murine experimental melanoma lung metastases [39]. Interestingly, in follicular thyroid neoplasms, both the downregulation and upregulation of TLR4 have been connected to primary metastases and the aggressiveness of cancer, whereas TLR2 expression associated with no clinicopathological parameter [40].

Based on our findings, a very strong TLR2 expression served as a positive prognostic factor among patients with lymph nodepositive disease (Dukes $\mathrm{C}$ stage). Additionally, patients who had a negative TLR2 expression exhibited a better DSS than patients with moderate TLR staining, although the number of patients with a negative TLR2 expression in the Dukes C subgroup was too small to draw any definitive conclusions. To our knowledge, this favorable TLR2 prognostic role in CRC has not been previously reported. TLR2 signaling may generate both proinflammatory and anti-inflammatory responses. The interaction between TLR2 and different co-receptors such as TLR1, TLR6, CD36, CD14, and Dectin-1 renders the TLR2 response even more complicated [41]. 
Table 4 Univariate and multivariate Cox regression analysis for disease-specific survival of colorectal cancer patients

\begin{tabular}{|c|c|c|c|c|c|c|}
\hline & \multicolumn{2}{|c|}{ Univariate analysis } & \multirow[t]{2}{*}{$p$ value $^{1}$} & \multicolumn{2}{|c|}{ Multivariate analysis } & \multirow[t]{2}{*}{$p$ value } \\
\hline & Hazard ratio & $95 \% \mathrm{CI}$ & & Hazard ratio & $95 \% \mathrm{CI}$ & \\
\hline \multicolumn{7}{|l|}{ Age } \\
\hline$<65$ & 1.00 & & & 1.00 & & \\
\hline$\geq 65$ & 1.42 & $1.14-1.75$ & 0.001 & 1.91 & $1.52-2.40$ & $<0.001$ \\
\hline \multicolumn{7}{|l|}{ Gender } \\
\hline Male & 1.00 & & & 1.00 & & \\
\hline Female & 0.96 & $0.78-1.18$ & 0.71 & 1.4 & $0.91-1.42$ & 0.248 \\
\hline \multicolumn{7}{|l|}{ Dukes stage } \\
\hline A & 1.00 & & & 1.00 & & \\
\hline $\mathrm{B}$ & 2.13 & $1.35-4.2$ & 0.005 & 2.33 & $1.32-4.09$ & 0.003 \\
\hline $\mathrm{C}$ & 5.3 & $3.74-11.2$ & $<0.001$ & 6.46 & $3.74-11.17$ & $<0.001$ \\
\hline $\mathrm{D}$ & 38.24 & $23.9-83.1$ & $<0.001$ & 44.62 & $23.9-83.3$ & $<0.001$ \\
\hline \multicolumn{7}{|c|}{ Tumor grade $(\mathrm{WHO})$} \\
\hline $1-2$ & 1.00 & & & 1.00 & & \\
\hline $3-4$ & 2.49 & $1.81-3.43$ & 0.001 & 2.13 & $1.52-3.0$ & $<0.001$ \\
\hline \multicolumn{7}{|l|}{ Location } \\
\hline Colon & 1.00 & & & 1.00 & & \\
\hline Rectum & 1.16 & $1.06-1.27$ & 0.001 & 0.87 & $0.64-1.2$ & 0.416 \\
\hline \multicolumn{7}{|l|}{ TLR4 } \\
\hline Strong & 1.00 & & & 1.00 & & \\
\hline Moderate & 0.8 & $0.59-1.07$ & 0.127 & 0.66 & $0.49-0.89$ & 0.007 \\
\hline Negative & 0.67 & $0.37-1.24$ & 0.202 & 0.67 & $0.36-1.25$ & 0.206 \\
\hline
\end{tabular}

Multivariate analysis included adjustments for gender, age, Dukes stage, and tumor grade

TLR4, Toll-like receptor 4; $C I$, confidence interval
We found that a strong TLR4 immunoreactivity predicts a worse prognosis in patients with a local colorectal tumor. More interestingly, among patients in the subgroups of Dukes A and B tumors (patients with no lymph node metastases), none of the patients lacking TLR4 expression in the tumor died from the disease. The number of patients in these subgroups was, however, quite small, such that further studies on larger cohorts are necessary.

Finding biomarkers remains pivotal in order to detect highrisk disease and to identify patients requiring adjuvant therapy. Our findings suggest that a strong TLR4 immunopositivity could identify those stage II patients requiring adjuvant therapy. A

Table 5 Multivariate Cox regression analysis for disease-specific survival of Dukes C subgroup colorectal cancer patients

\begin{tabular}{lllr}
\hline TLR2 expression & Hazard ratio & $95 \%$ CI & $p$ value \\
\hline Strong & 1.00 & & \\
Moderate & 2.63 & $1.56-4.44$ & $<0.001$ \\
Negative & 1.26 & $0.47-3.4$ & 0.646 \\
\hline
\end{tabular}

Multivariate analysis included adjustment for gender, age, Dukes stage, and tumor grade

TLR2, Toll-like receptor 2; CI, confidence interval negative TLR4 immunostaining, however, could possibly spare some lower stage patients from unnecessary follow-up. In lymph node-positive disease, both a negative and a very strong TLR2 expression might serve as a predictive marker to identify patients that could be spared from adjuvant therapy.

The strength of our work lies in the large and wellcharacterized patient cohort, which allowed us to focus on different stage subgroups. The follow-up time in this cohort is also rather long, which allowed us to determine if patients were genuinely cured of cancer. On the other hand, the cohort is quite old. One strength to using an older cohort lies in the less frequent administration of adjuvant therapy at that time, whereby we can observe a more natural course of disease following surgery. Moreover, one drawback to using an older cohort lies in the harvesting of lymph nodes from surgical specimens, which relied on significantly inferior practices than those used today. In older series, thus, there might be a small migration of stage [42]. Unsurprisingly, surgical techniques have changed somewhat and operations along embryological planes, total mesorectal excision (TME), and complete mesocolic excision (CME) now represent standard procedures in CRC surgery [43, 44]. Another disadvantage to using an older cohort lies in the different staging classifications used at that time compared with the staging methods currently employed. The TMA technique allows the 
analysis of a large patient cohort, although inadequate representation of the whole tissue section might represent a limitation of this technique. By punching multiple areas of the primary tumor, however, we minimize this limitation [45].

\section{Conclusions}

To our knowledge, this represents the first study to report a predictive role of TLR2 in CRC. A strong TLR2 immunoexpression served as a positive prognostic factor in lymph node-positive CRC patients. A strong TLR4 immunoexpression, however, predicted a worse prognosis in patients with local CRC. In particular, none of the patients with a local, TLR4-negative tumor died from the disease. Further investigations are necessary in order to validate these findings.

Acknowledgments We thank Päivi Peltokangas and Elina Aspiala for their exceptional technical assistance.

Author contributions $\mathrm{CH}, \mathrm{CB}$, and $\mathrm{JH}$ were responsible for the conception and design of the study. IBL, CB, HM, and SK collected and processed the data. JH contributed to specimen preparation. IBL and JH evaluated the histological and immunohistochemical findings. IBL, HM, CH, and $\mathrm{CB}$ analyzed the data and interpreted the results. IBL drafted the manuscript. All authors have agreed to the content of the manuscript, provided revisions as necessary to the manuscript, and provided their final approval to the current version of the submitted manuscript.

Funding information Open access funding provided by University of Helsinki including Helsinki University Central Hospital. This study was financially supported by the Competitive State Research Financing of the Expert Responsibility Area of Helsinki University Hospital (CH and IBL), the Kurt och Doris Palander Foundation (IBL), the Finnish Cancer Foundation $(\mathrm{CH}$ and $\mathrm{JH})$, Finska Läkaresällskapet $(\mathrm{CB})$, the K. Albin Johansson Foundation (CB), and the Sigrid Juselius Foundation $(\mathrm{CH})$.

\section{Compliance with ethical standards}

The Surgical Ethics Committee of Helsinki University Hospital (Dnro HUS 226/E6/06, extension TMK02 \$66 17.4.2013) approved the study protocol. The National Supervisory Authority of Health and Welfare granted permission to use tissue archive samples retrospectively without requiring individual informed consent (Valvira Dnro 10041/06.01.03.01/2012).

Competing interests The authors declare that they have no competing interests.

Open Access This article is licensed under a Creative Commons Attribution 4.0 International License, which permits use, sharing, adaptation, distribution and reproduction in any medium or format, as long as you give appropriate credit to the original author(s) and the source, provide a link to the Creative Commons licence, and indicate if changes were made. The images or other third party material in this article are included in the article's Creative Commons licence, unless indicated otherwise in a credit line to the material. If material is not included in the article's Creative Commons licence and your intended use is not permitted by statutory regulation or exceeds the permitted use, you will need to obtain permission directly from the copyright holder. To view a copy of this licence, visit http://creativecommons.org/licenses/by/4.0/.

\section{References}

1. Bray F, Ferlay J, Soerjomataram I, Siegel RL, Torre LA, Jemal A (2018) Global cancer statistics 2018: GLOBOCAN estimates of incidence and mortality worldwide for 36 cancers in 185 countries. CA Cancer J Clin 68:68394-68424. https://doi.org/10.3322/caac.21492

2. Arnold M, Sierra MS, Laversanne M, Soerjomataram I, Jemal A, Bray F (2017) Global patterns and trends in colorectal cancer incidence and mortality. Gut 66:683-691. https://doi.org/10.1136/ gutjnl-2015-310912

3. Favoriti P, Carbone G, Greco M, Pirozzi F, Pirozzi REM, Corcione F (2016) Worldwide burden of colorectal cancer: a review. Updat Surg 68:7-11. https://doi.org/10.1007/s13304-016-0359-y

4. Böckelman C, Engelmann BE, Kaprio T, Hansen TF, Glimelius B (2015) Risk of recurrence in patients with colon cancer stage II and III: a systematic review and meta-analysis of recent literature. Acta Oncol 54:5-16. https://doi.org/10.3109/0284186X.2014.975839

5. Sato Y, Goto Y, Narita N, Hoon DSB (2009) Cancer cells expressing Toll-like receptors and the tumor microenvironment. Cancer Microenviron 2 Suppl 1(S1):205-214. https://doi.org/10.1007/ s12307-009-0022-y

6. Shrihari TG (2017) Inflammation-related cancer or cancer-related inflammation. Eur Res J 4:1-5. https://doi.org/10.18621/eurj.312327

7. Kersten C, Louhimo J, Ålgars A, Lahdesmaki A, Cvancerova M, Stenstedt K, Haglund C, Gunnarsson U et al (2013) Increased Creactive protein implies a poorer stage-specific prognosis in colon cancer. Acta Oncol 5:1691-1698. https://doi.org/10.3109/ 0284186X.2013.835494

8. Maeda K, Shibutani M, Otani H, Nagahara H, Ikeya T, Iseki Y, Tanaka H, Muguruma K, Hirakawa K (2015) Inflammation-based factors and prognosis in patients with colorectal cancer. World $\mathrm{J}$ Gastrointest Oncol 7:111-117. https://doi.org/10.4251/wjgo.v7.i8.111

9. Richards CH, Roxburgh CSD, Powell AG, Foulis AK, Horgan PG, McMillan DC (2014) The clinical utility of the local inflammatory response in colorectal cancer. Eur J Cancer 50:309-319. https://doi. org/10.1016/j.ejca.2013.09.00

10. Chen K, Huang J, Gong W, Iribarren P, Dunlop NM, Wang JM (2007) Toll-like receptors in inflammation, infection and cancer. Int Immunopharmacol 7:1271-1285. https://doi.org/10.1016/j. intimp.2007.05.01

11. Basith S, Manavalan B, Yoo TH, Kim SG, Choi S (2012) Roles of Toll-like receptors in cancer: a double-edged sword for defense and offense. Arch Pharm Res 35:1297-1316. https://doi.org/10.1007/ s12272-012-0802-7

12. Dajon M, Iribarren K, Cremer I (2017) Toll-like receptor stimulation in cancer: a pro- and anti-tumor double-edged sword. Immunobiology 222:89-100. https://doi.org/10.1016/j.imbio. 2016.06.009

13. Vijay K (2018) Toll-like receptors in immunity and inflammatory diseases: past, present, and future. Int Immunopharmacol 59:391412. https://doi.org/10.1016/j.intimp.2018.03.002

14. O'Neill LAJ, Golenbock D, Bowie AG (2013) The history of Tolllike receptors - redefining innate immunity. Nat Rev Immunol 13: 453-460. https://doi.org/10.1038/nri3446

15. Iwasaki A, Medzhitov R (2004) Toll-like receptor control of the adaptive immune responses. Nat Immunol 5:987-995. https://doi. org/10.1038/ni1112

16. Yu L, Wang L, Chen S (2010) Endogenous Toll-like receptor ligands and their biological significance. J Cell Mol Med 14:25922603. https://doi.org/10.1111/j.1582-4934.2010.01127.x

17. Devaraj S, Dasu MR, Rockwood J, Winter W, Griffen SC, Jialal I (2008) Increased Toll-like receptor (TLR) 2 and TLR4 expression in monocytes from patients with type 1 diabetes: further evidence of a proinflammatory state. J Clin Endocrinol Metab 93:578-583. https://doi.org/10.1210/jc.2007-2185 
18. Dasu MR, Devaraj S, Park S, Jialal I (2010) Increased Toll-like receptor (TLR) activation and TLR ligands in recently diagnosed type 2 diabetic subjects. Diabetes Care 33:861-868. https://doi.org/ $10.2337 / \mathrm{dc} 09-1799$

19. Bonen DK, Ogura Y, Nicolae DL, Inohara N, Saab L, Tanabe T, Chen FF, Foster SJ, Duerr RH, Brant SR, Cho JH, Nuñez G (2003) Crohn's disease-associated NOD2 variants share a signaling defect in response to lipopolysaccharide and peptidoglycan. Gastroenterology 124:140146. https://doi.org/10.1053/gast.2003.50019

20. Fukata M, Chen A, Vamadevan AS, Cohen J, Breglio K, Krishnareddy S, Hsu D, Xu R, Harpaz N, Dannenberg AJ, Subbaramaiah K, Cooper HS, Itzkowitz SH, Abreu MT (2007) Toll-like receptor- 4 promotes the development of colitisassociated colorectal tumors. Gastroenterology 133:1869-1881. https://doi.org/10.1053/j.gastro.2007.09.008

21. Huang B, Zhao J, Unkeless JC, Feng ZH, Xiong H (2008) TLR signaling by tumor and immune cells: a double-edged sword. Oncogene 27:218-224. https://doi.org/10.1038/sj.onc. 1210904

22. Chen R, Alvero AB, Silasi D-A, Steffensen KD, Mor G (2008) Cancers take their Toll- the function and regulation of Toll-like receptors in cancer cells. Oncogene 27:225-233. https://doi.org/ 10.1038/sj.onc. 1210907

23. Yu L, Wang L, Li M, Zhong J, Wang Z, Chen S (2010) Expression of Toll-like receptor 4 is down-regulated during progression of cervical neoplasia. Cancer Immunol Immunother 59:1021-1028. https://doi.org/10.1007/s00262-010-0825-1

24. Paarnio K, Väyrynen S, Klintrup K, Ohtonen P, Mäkinen MJ, Mäkelä J, Karttunen TJ (2017) Divergent expression of bacterial wall sensing Toll-like receptors 2 and 4 in colorectal cancer. WJG 23:4831-4838. https://doi.org/10.3748/wjg.v23.i26.4831

25. Eiró N, Ovies C, Fernandez-Garcia B, Álvarez-Cuesta CC, González L, González LO, Vizoso FJ (2013) Expression of TLR3, 4, 7 and 9 in cutaneous malignant melanoma: relationship with clinicopathological characteristics and prognosis. Arch Dermatol Res 305:59-67. https:// doi.org/10.1007/s00403-012-1300-y

26. Nihon-Yanagi Y, Terai K, Murano T, Matsumoto T, Okazumi S (2012) Tissue expression of Toll-like receptors 2 and 4 in sporadic human colorectal cancer. Cancer Immunol Immunother 61:71-77. https://doi.org/10.1007/s00262-011-1085-4

27. Simiantonaki N, Kurzik-Dumke U, Karyofylli G, Jayasinghe C, Michel-Schmidt R, Kirkpatrick C (2007) Reduced expression of TLR4 is associated with the metastatic status of human colorectal cancer. Int J Mol Med 20:21-29. https://doi.org/10.3892/ijmm.20.1.21

28. Tsikitis VL, Larson DW, Huebner M, Lohse CM, Thompson PA (2014) Predictors of recurrence free survival for patients with stage II and III colon cancer. BMC Cancer 14:10-17. https://doi.org/10. 1186/1471-2407-14-336

29. Eiró N, González L, González LO, Fernandez-Garcia B, Andicoechea A, Barbón E (2013) Toll-like receptor-4 expression by stromal fibroblasts is associated with poor prognosis in colorectal cancer. J Immunother 36:342-349. https://doi.org/10.1097/CJI. 0b013e31829d85e6

30. Huhta H, Helminen O, Lehenkari PP, Saarnio J, Karttunen TJ, Kauppila JH (2016) Toll-like receptors 1, 2, 4 and 6 in esophageal epithelium, Barrett's esophagus, dysplasia and adenocarcinoma. Oncotarget 7:23658-23667. https://doi.org/10.18632/oncotarget.8151

31. Mäkinen LK, Atula T, Häyry V, Jouhi L, Datta N, Lehtonen S, Ahmed A, Mäkitie AA, Haglund C, Hagström J (2015) Predictive role of Toll-like receptors 2,4 , and 9 in oral tongue squamous cell carcinoma. Oral Oncol 51:96-102. https://doi.org/10.1016/j. oraloncology.2014.08.017

32. Mäkinen LK, Ahmed A, Hagström J, Lehtonen S, Mäkitie AA, Salo T, Haglund C, Atula T (2016) Toll-like receptors 2, 4, and 9 in primary, metastasized, and recurrent oral tongue squamous cell carcinomas. J Oral Pathol Med 45:338-345. https://doi.org/10. 1111/jop. 12373

33. Lanki MA, Seppänen HE, Mustonen HK, Böckelman C, Juuti AT, Hagström JK, Haglund CH (2018) Toll-like receptor 2 and Toll-like receptor 4 predict favorable prognosis in local pancreatic cancer. Tumour Biol 40:1010428318801188. https://doi.org/10.1177/ 1010428318801188

34. Tye H, Kennedy CL, Najdovska M, McLeod L, McCormack W, Hughes N, Dev A, Sievert W, Ooi CH, Ishikawa TO, Oshima H, Bhathal PS, Parker AE, Oshima M, Tan P, Jenkins BJ (2012) STAT3-driven upregulation of TLR2 promotes gastric tumorigenesis independent of tumor inflammation. Cancer Cell 22:466-478. https://doi.org/10.1016/j.ccr.2012.08.010

35. González-Reyes S, Marín L, González L, González LO, Del Casar JM, Lamelas ML, González-Quintana JM, Vizoso FJ (2010) Study of TLR3, TLR4 and TLR9 in breast carcinomas and their association with metastasis. BMC Cancer 10:665. https://doi.org/10.1186/ 1471-2407-10-665

36. González-Reyes S, Fernández JM, González LO, Aguirre A, Suárez A, González JM, Escaff S, Vizoso FJ (2011) Study of TLR3, TLR4, and TLR9 in prostate carcinomas and their association with biochemical recurrence. Cancer Immunol Immunother 60:217-226. https://doi.org/10.1007/s00262-010-0931-0

37. Kim KH, Jo MS, Suh DS, Yoon MS, Shin DH, Lee JH, Choi KU (2012) Expression and significance of the TLR4/MyD88 signaling pathway in ovarian epithelial cancers. World J Surg Oncol 10:193. https://doi.org/10.1186/1477-7819-10-193

38. Zhang Y-B, He F-L, Fang M, Hua T-F, Hu B-D, Zhang Z-H, Cao Q, Liu RY (2008) Increased expression of Toll-like receptors 4 and 9 in human lung cancer. Mol Biol Rep 36:1475-1481. https://doi.org/ 10.1007/s11033-008-9338-9

39. Lee C-H, Wu C-L, Shiau A-L (2010) Toll-like receptor 4 signaling promotes tumor growth. J Immunother 33:73-82. https://doi.org/ 10.1097/CJI.0b013e3181b7a0a4

40. Hagström J, Heikkilä A, Siironen P, Louhimo J, Heiskanen I, Mäenpää H, Arola J, Haglund C (2012) TLR-4 expression and decrease in chronic inflammation: indicators of aggressive follicular thyroid carcinoma. J Clin Pathol 65:333-338. https://doi.org/10. 1136/jclinpath-2011-200402

41. Frosali S, Pagliari D, Gambassi G, Landolfi R, Pandolfi F, Cianci R (2015) Review article how the intricate interaction among Toll-like receptors, microbiota, and intestinal immunity can influence gastrointestinal pathology. J Immunol Res 2015:489821-489812. https:// doi.org/10.1155/2015/489821

42. Derwinger K, Carlsson G, Gustavsson B (2007) Stage migration in colorectal cancer related to improved lymph node assessment. Eur J Surg Oncol 33:849-853. https://doi.org/10.1016/j.ejso.2007.02.003

43. Gouvas N, Agalianos C, Papaparaskeva K, Perrakis A, Hohenberger W, Xynos E (2016) Surgery along the embryological planes for colon cancer: a systematic review of complete mesocolic excision. Int J Color Dis 31(9):1577-1594. https://oi.org/10.1007/s00384-016-2626-2

44. Garlipp B, Ptok H, Schmidt U, Stübs P, Scheidbach H, Meyer F, Gastinger I, Lippert H (2012) Factors influencing the quality of total mesorectal excision. Br J Surg 99:714-720. https://doi.org/10. 1002/bjs. 8692

45. Kyndi M, Sørensen FB, Knudsen H, Overgaard M, Nielsen HM, Andersen J, Overgaard J (2008) Tissue microarrays compared with whole sections and biochemical analyses. A subgroup analysis of DBCG 82 b\&c. Acta Oncol 47:591-599. https://doi.org/10.1080/ 02841860701851871

Publisher's note Springer Nature remains neutral with regard to jurisdictional claims in published maps and institutional affiliations. 